\title{
Seasonal variability of sea-surface temperature fronts associated with large marine ecosystems in the north Indian Ocean
}

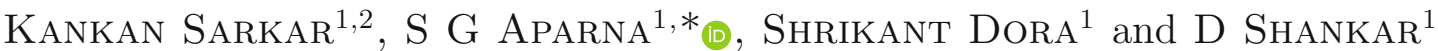 \\ ${ }^{1}$ CSIR-National Institute of Oceanography, Dona Paula, Goa 403 004, India. \\ ${ }^{2}$ Department of Mathematics, Malda College, Malda, West Bengal 732 101, India. \\ ${ }^{*}$ Corresponding author. e-mail: aparna@nio.org
}

MS received 13 June 2018; revised 28 September 2018; accepted 3 October 2018; published online 18 December 2018

We use 14 years of satellite-derived sea-surface temperature (SST) data to compute a monthly frontal probability index (FPI) to determine the existence of a front in a pixel. A persistent SST front is deemed to exist if the FPI in a narrow region exceeds that in the surrounding ocean. We describe the seasonal variability of 17 persistent SST fronts (eight associated with the shelf-slope boundary and five with the mixing between different water masses) in the north Indian Ocean. Only weak fronts exist during a few months in the strong upwelling regimes off Somalia and Oman.

Keywords. SST fronts; frontal systems; Arabian Sea; Bay of Bengal; potential fishing zones.

\section{Introduction}

Sea-surface temperature (SST) fronts are narrow regions in the ocean across which high horizontal temperature gradients are observed; they occur on a variety of temporal and spatial scales, with the horizontal extent varying from a few hundred metres to thousands of kilometres and vertical extent from a few tens of metres to a few hundred metres (Belkin and Cornillon 2007; Belkin et al. 2009). SST fronts tend to be more productive owing to an increased supply of nutrients and therefore tend to be richer in fish than the surrounding ocean (see, e.g., Maul et al. 1984; Solanki et al. 2008; Mahadevan 2014). The characteristics of SST fronts depend on where they form - e.g., tropical fronts tend to be associated with weaker temperature gradients than sub-tropical or polar fronts (Vipin et al. 2015) - and the oceanic processes responsible for their formation - for example, in the tropics, oceanic fronts with hightemperature gradients tend to be restricted to upwelling regimes associated with westernboundary currents (Evans and Brown 1981).

SST fronts are also seen in the north Indian Ocean (NIO), a tropical basin, but most tend to be short-lived, with a lifespan of the order of a week. Nevertheless, some of these short-lived fronts also tend to be more productive than the surrounding ocean (Vipin et al. 2015). Such short-lived fronts tend to move considerably owing to advection by the large-scale currents. Even in the NIO, however, some fronts tend to be quasi-stationary and persist longer, with some fronts surviving over

Supplementary material pertaining to this article is available on the Journal of Earth System Science website (http://www. ias.ac.in/Journals/Journal_of_Earth_System_Science). 


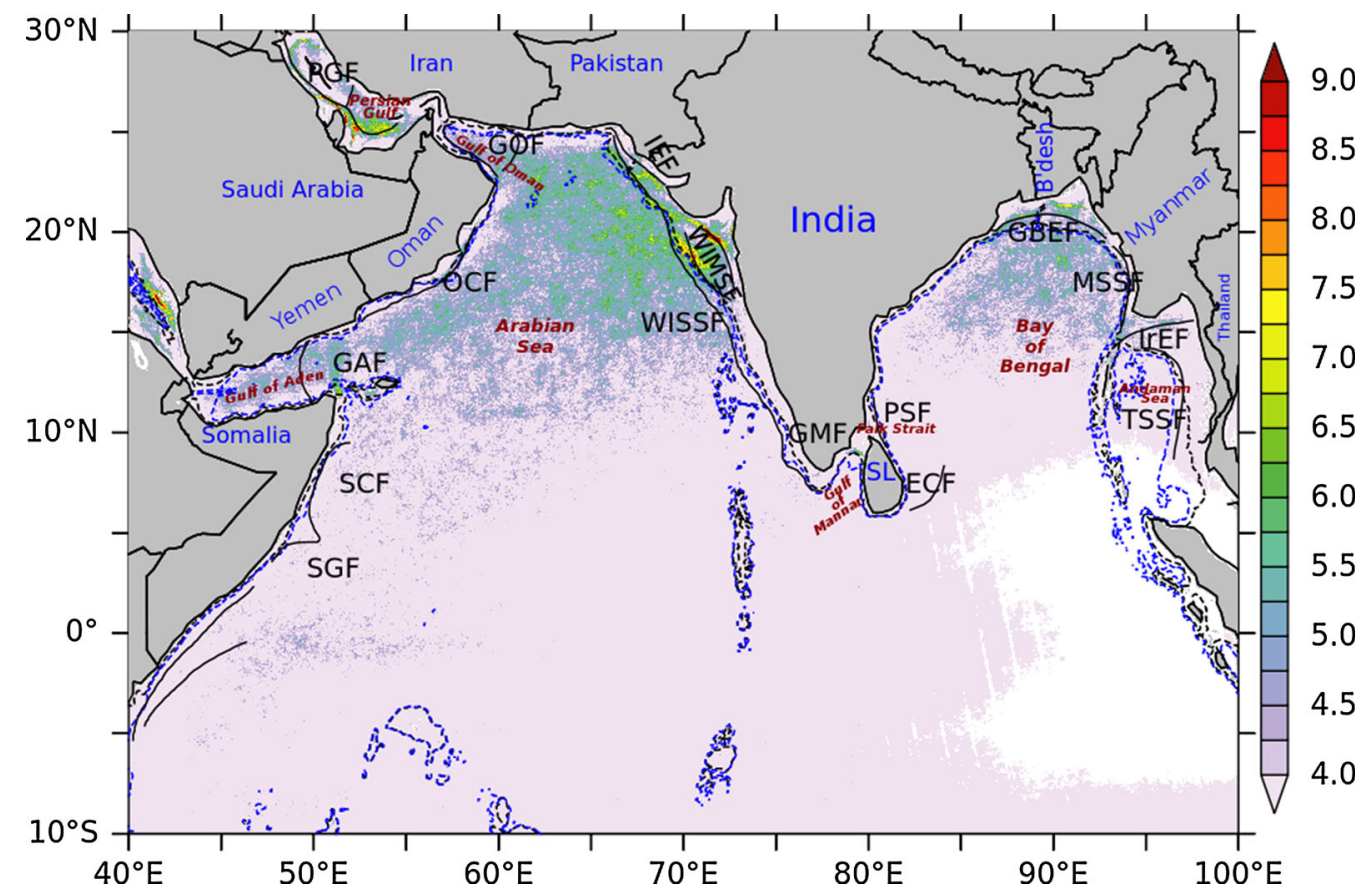

Figure 1. The annual FPI in the NIO. The frontal systems identified by Belkin and Cornillon (2007) are marked using black curves; the acronyms are as in table 1 . The $200 \mathrm{~m}(1000 \mathrm{~m})$ depth contours are plotted using black (blue) dashed curves. SL: Sri Lanka; B'desh: Bangladesh.

a season. These quasi-stationary fronts tend to form in the same region and season year after year.

Such persistent frontal systems tend to have larger spatial scales as well. Fourteen such frontal systems, eight in the Arabian Sea and six in the Bay of Bengal (BoB), were identified by Belkin and Cornillon (2007, hereafter BC07); these fronts are associated with large marine ecosystems (LMEs) in these sub-basins of the NIO (figure 1). Given the strong seasonal variation in the NIO, however, it is likely that all these fronts do not exist throughout the year. In this paper, we use a frontal probability index (FPI) to delineate the fronts month by month and show that some of these fronts exist only over a part of the year. The data and methods are described in section 2 , the seasonal variability is presented in section 3 and section 4 concludes this paper.

\section{Data and methods}

We use Level-3 MODIS (moderate resolution imaging spectroradiometer) Aqua SST data for 20032016; an earlier, but a preliminary analysis used data from 2003 to 2013 (Sarkar et al. 2015). These data are available at a spatial (temporal) resolution of $4 \mathrm{~km}$ (1 day) from http://oceandata. sci.gsfc.nasa.gov/. The domain extends from $10^{\circ} \mathrm{S}$ to $30^{\circ} \mathrm{N}$ and $40^{\circ} \mathrm{E}$ to $100^{\circ} \mathrm{E}$.

SST fronts were delineated for each day during 2003-2016 using the single-image-edge-detection algorithm (Cayula and Cornillon 1992). This algorithm is available as a software package called Marine Geospatial and Ecology Tools (MG ET: http://code.env.duke.edu/projects/mget/; Roberts et al. 2010), which runs on the ArcGIS platform. We used the module fronts.py and the image-processing tools, which were available for the MATLAB platform, but converted these codes to GNU Octave (http://www.gnu.org/software/ octave/), Fortran and C to enable usage on any computer (including on a ship) and to increase the processing speed. The parameter values used were as in Vipin et al. (2015): the window size was 32 pixels, the mean temperature difference across the front (cutoff) was $0.15^{\circ} \mathrm{C}$, the critical function was 0.72 , and the single-population cohesion and global-population cohesion parameters were 0.9 and 0.92 , respectively.

After delineating the SST fronts, we computed the monthly composite of the occurrence of SST fronts (not of SST) at each pixel in the domain: all available SST front data obtained from successive images for a month were combined. This technique 
has been used to describe the seasonal distribution of fronts in different parts of the world oceans (Ullman and Cornillon 1999; Hickox et al. 2000; Belkin et al. 2009; Miller 2009). From the monthly composite of the occurrence of fronts, we estimated the FPI, $P_{\mathrm{F}}$, which gives the probability (in percentage) of the occurrence of a front in a particular pixel. For a pixel, the FPI is given by

$$
P_{\mathrm{F}}=100 \times \frac{N_{\mathrm{SSTF}}}{N_{\text {good }}} \%,
$$

where $N_{\mathrm{SSTF}}$ is the total number of occurrences of SST fronts for the given month for the pixel and $N_{\text {good }}$ is the number of good SST data values. This method of computation of FPI was earlier used by Ullman and Cornillon (1999) and Belkin and Cornillon (2007).

The drawback of this formula is that it can yield a misleading result of high FPI when data availability is low. For example, if $N_{\text {good }}=5$ at a grid point and $N_{\mathrm{SSTF}}$ also equals 5 , then this formula yields $P_{\mathrm{F}}=100 \%$, which is misleading as we do not have data for most days of the month. To avoid such false high FPI, we set a minimum threshold, $N_{\text {threshold }}$, for $N_{\text {good }}$ for each pixel for a given month and computed the FPI only when $N_{\text {good }} \geq N_{\text {threshold. }}$. The threshold observation value, $N_{\text {threshold }}$ was estimated as the difference between the central tendency, given by the median, and the standard deviation. $N_{\text {threshold }}$ for 12 months is listed in table 1 . The median and standard deviation for each month were computed by stacking all the available data (for all years for that month) for all pixels in the domain. The basic assumption underlying this formula is that most of the values are expected to lie within one standard deviation of the central tendency. The existence of outliers and the uneven spatial distribution of data imply that the median is a better estimate of the central tendency than the mean.

Most of the SST fronts in our study domain tend to move fast owing to advection, leading Vipin et al. (2015) to use six satellite passes in a day to map the movement. Since our focus is on the seasonal variability, we created monthly

Table 1. The seasonal variation of the frontal systems.

\begin{tabular}{|c|c|c|c|c|c|c|c|c|c|c|c|c|c|}
\hline Sl. no. & Acronym & $\mathrm{J}$ & $\mathrm{F}$ & M & A & $\mathrm{M}$ & $\mathrm{J}$ & $\mathrm{J}$ & $\mathrm{A}$ & $\mathrm{S}$ & $\mathrm{O}$ & $\mathrm{N}$ & $\mathrm{D}$ \\
\hline 1 & $\mathrm{SCF}$ & $\circ$ & $\circ$ & ○ & $\circ$ & $\checkmark$ & $\checkmark$ & $\checkmark$ & $\circ$ & $\circ$ & $\circ$ & $\circ$ & $\circ$ \\
\hline 2 & SGF & $\circ$ & $\circ$ & $\circ$ & $\circ$ & $\checkmark$ & $\checkmark$ & $\checkmark$ & $\checkmark$ & $\circ$ & $\circ$ & $\circ$ & $\circ$ \\
\hline 3 & GAF & $\circ$ & $\checkmark$ & $\checkmark$ & $\checkmark$ & $\checkmark$ & $\checkmark$ & $\checkmark$ & $\checkmark$ & $\checkmark$ & $\checkmark$ & $\checkmark$ & $\circ$ \\
\hline 4 & $\mathrm{OCF}$ & $\circ$ & $\checkmark$ & $\checkmark$ & $\checkmark$ & $\checkmark$ & ○ & - & - & $\checkmark$ & $\checkmark$ & $\circ$ & $\circ$ \\
\hline 5 & $\mathrm{GOF}$ & $\circ$ & $\circ$ & ० & $\circ$ & $\circ$ & $\circ$ & $\circ$ & $\circ$ & $\checkmark$ & $\checkmark$ & $\checkmark$ & $\circ$ \\
\hline 6 & PGF & $\checkmark$ & $\checkmark$ & $\checkmark$ & $\checkmark$ & $\checkmark$ & $\checkmark$ & $\checkmark$ & $\checkmark$ & $\checkmark$ & $\checkmark$ & $\checkmark$ & $\checkmark$ \\
\hline 7 & PUF & $\circ$ & $\circ$ & $\checkmark$ & $\checkmark$ & $\checkmark$ & $\checkmark$ & $\circ$ & $\circ$ & $\checkmark$ & $\checkmark$ & $\checkmark$ & $\circ$ \\
\hline 8 & IEF & $\checkmark$ & $\checkmark$ & $\checkmark$ & $\checkmark$ & $\circ$ & ० & $\circ$ & $\circ$ & o & $\checkmark$ & $\checkmark$ & $\checkmark$ \\
\hline 9 & WIMSF & $\checkmark$ & $\checkmark$ & $\checkmark$ & $\checkmark$ & $\circ$ & ० & - & $\circ$ & o & $\circ$ & $\checkmark$ & $\checkmark$ \\
\hline 10 & WISSF & $\checkmark$ & $\checkmark$ & $\checkmark$ & $\checkmark$ & $\circ$ & ० & - & $\circ$ & ○ & $\circ$ & $\checkmark$ & $\checkmark$ \\
\hline 11 & GMF & $\checkmark$ & ○ & $\checkmark$ & $\checkmark$ & $\circ$ & $\checkmark$ & $\checkmark$ & $\checkmark$ & $\checkmark$ & $\checkmark$ & $\circ$ & $\checkmark$ \\
\hline 12 & $\mathrm{ECF}$ & $\circ$ & ○ & ० & $\circ$ & $\checkmark$ & $\checkmark$ & ○ & $\circ$ & $\checkmark$ & $\circ$ & $\circ$ & $\checkmark$ \\
\hline 13 & PSF & $\circ$ & ○ & $\checkmark$ & $\checkmark$ & $\checkmark$ & $\checkmark$ & $\checkmark$ & $\checkmark$ & $\checkmark$ & $\circ$ & $\circ$ & $\circ$ \\
\hline 14 & GBEF & $\checkmark$ & $\checkmark$ & ० & $\circ$ & $\circ$ & - & - & $\circ$ & o & $\checkmark$ & $\checkmark$ & $\checkmark$ \\
\hline 15 & MSSF & $\checkmark$ & $\checkmark$ & ० & $\circ$ & - & - & - & - & - & $\circ$ & $\checkmark$ & $\checkmark$ \\
\hline 16 & $\mathrm{IrEF}$ & $\checkmark$ & ○ & ० & $\checkmark$ & - & - & - & - & - & $\circ$ & $\circ$ & $\checkmark$ \\
\hline \multirow[t]{2}{*}{17} & TSSF & $\circ$ & ○ & ० & $\circ$ & - & - & - & - & - & ○ & $\circ$ & $\circ$ \\
\hline & $N_{\text {threshold }}$ & 103 & 110 & 136 & 117 & 83 & 50 & 40 & 28 & 48 & 66 & 73 & 84 \\
\hline
\end{tabular}

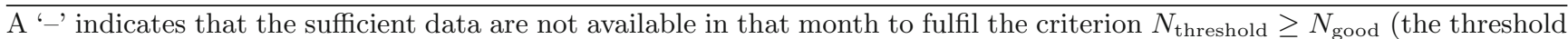
observation value, $N_{\text {threshold, }}$, is listed in the last row for each month), a ' $\checkmark$ ' indicates that the front is observed in that particular month, and a ' $\mathrm{O}$ ' indicates that the front is not observed. The acronyms are as follows. SCF: Somalia Coastal Front; SGF: Somalia Gyres Front; GAF: Gulf of Aden Front; OCF: Oman Coastal Front; GOF: Gulf of Oman Front; PGF: Persian Gulf Front; PUF: Pakistan Upwelling Front; IEF: Indus Estuarine Front; WIMSF: West India Mid-Shelf Front; WISSF: West India Shelf-Slope Front; GMF: Gulf of Mannar Front; ECF: East Ceylon Front; PSF: Palk Strait Front; GBEF: Ganga-Brahmaputra Estuarine Front; MSSF: Myanmar Shelf-Slope Front; IrEF: Irrawaddy Estuarine Front; TSSF: Thailand Shelf-Slope Front. These acronyms, except for SGF, PUF and GMF, are as in BC07. The serial numbers in the first column are used in figure 2 . 
composite maps: the composite eliminates all variability within a month, but shows which regions are more likely to be associated with SST fronts. In the composite for, say, January, all the available data for SST fronts for each day in January during 2003-2016 (maximum possible for January is $31 \times 14=434$ days) were used to compute the FPI.

\section{Seasonal variability of fronts in the LMEs}

BC07 identified 14 frontal systems in the Arabian Sea and BoB (figure 1). We discuss briefly the seasonal variability of each of them, moving counterclockwise from the Arabian Sea into the $\mathrm{BoB}$; the names and acronyms of these fronts are as in BC07. In addition, we show that the Somalia Current Front (SCF) identified by BC07 is associated with two distinct frontal systems, one associated with the boundary current and another with the gyres associated with Somali Current, and that a front mentioned, but not marked, by $\mathrm{BC} 07$ does exist off the coast of Pakistan (Pakistan Upwelling Front (PUF)). Furthermore, we identify one new front in the Gulf of Mannar, the Gulf of Mannar Front (GMF). These 17 fronts are listed in table 1 and figure 2 shows the monthly FPI maps that form the basis for the following description. See figure 1 for the location of the fronts mentioned by $\mathrm{BC} 07$, figure 2 for the seasonal variation of the 17 fronts and table 1 for a monthly summary of the existence of these fronts; the fronts are numbered in the table and the description below to facilitate their identification in figure 2.

The Somalia Coastal Front (SCF, 1) is not evident in the annual FPI map, but a weak frontal system associated with the boundary

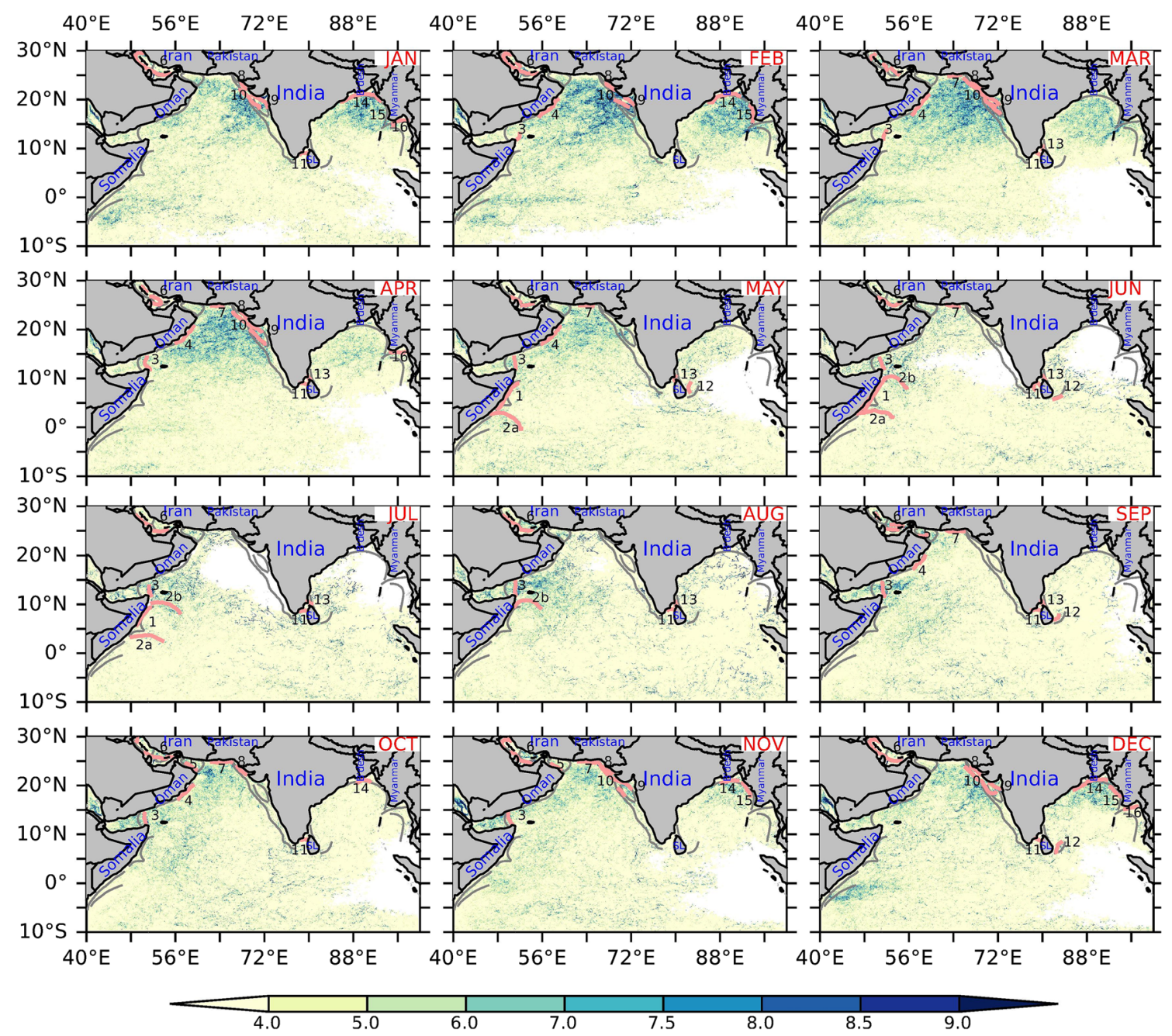

Figure 2. Monthly FPI computed from MODIS Aqua SST data for 2003-2016. The grey curves are the frontal systems identified by Belkin and Cornillon (2007) and shown in the annual FPI map in figure 1. The seasonal fronts are denoted by the pink curves and the numbers are as in section 3 and table 1. SL: Sri Lanka; B'desh: Bangladesh. 
current off Somalia is evident during May-July over a part of the shelf-slope boundary. Although the Somali Current is the strongest boundary current in the NIO and has been associated with strong upwelling, the strong upwelling front expected in this region (Evans and Brown 1981) is not seen.

The Somalia Gyres Front (SGF, 2) was combined with the SCF by BC07, but it is also not evident in the annual FPI map. Two distinct fronts, one each associated with the Southern Gyre (SGF2a) and the Great Whirl (SGF-2b), are, however, seen during May-August. The Southern Gyre is the southernmost of the major gyres associated with the Somali Current and is seen just north of the equator (Bruce 1968); the Great Whirl forms farther north, near the northeastern boundary of Somalia (Bruce 1968). We do not distinguish between the fronts associated with these two gyres in spite of the distance separating them and assign the same number to both of them though the SGF$2 \mathrm{a}$ is seen during May-July and the SGF-2b during June-August.

The Gulf of Aden Front (GAF, 3) is observed in the annual FPI map at the mouth of the gulf, but about a degree east of the $51^{\circ} \mathrm{E}$ location reported earlier (BC07). The GAF extends across the mouth of the Gulf of Aden, from the northeastern tip of Somalia to the coast of Yemen. It starts off as a broad spread of high FPI in February-March; the FPI increases through April-May and peaks during May-September; the FPI decreases in October and the GAF is not seen during DecemberJanuary.

The Oman Coastal Front (OCF, 4) exists only during a few months of the year. The FPI is higher offshore of the OCF, but patches of higher FPI are seen in the OCF regime during February-March. The extent of high FPI increases during April-May, but the FPI decreases during the summer monsoon (June-August), but data are sparse during July-August. The OCF reappears as a weak front in September, is at its peak during October, and collapses in November.

The Gulf of Oman Front (GOF, 5) exists as two distinct patches, one along the northern coast of Oman (coastal GOF or CGOF) and another across the mouth of the Gulf of Oman, from the coast of Oman to the coast of Iran (open-ocean GOF or OOGOF). Although a broad spread of FPI above the surroundings is seen in the neighbourhood of OOGOF in several months, OOGOF never appears as a distinct front. High FPI is evident in the
CGOF regime during September-November, but the peak is restricted to October.

The Persian Gulf Front (PGF, 6) is the only frontal system that exists throughout the year, but its location, marked closer to the Arabian peninsula by BC07, shifts seasonally across the gulf, moving from the coast of the Arabian peninsula (November-February and May-September) to the coast of Iran (August-November). During MarchApril and again during September-October, the PGF is seen in the middle of the Persian Gulf, away from both coastal regimes. The data also suggest that the front extends from $25.5^{\circ}$ to $30^{\circ} \mathrm{N}$ only during November-February; it is shorter and terminates farther south during the other months.

The Pakistan Upwelling Front (PUF, 7) was mentioned by $\mathrm{BC} 07$, but not marked. This front exists as a regime of moderately high FPI during March-June off the coast of Pakistan; it forms again during September, but is strong only during October-November, after which it collapses. This front seems to be driven by local upwelling favourable winds during March-June and again during October-November. It is not seen during the winter monsoon (December-February), when remotely forced downwelling dominates in the eastern and northern Arabian Sea, or during the peak of the summer monsoon in July-August, when the upwelling is forced remotely (Shankar et al. 2002).

The Indus Estuarine Front (IEF, 8) is seen off the coast of Pakistan and Gujarat during OctoberApril. At its western end, it may merge into the PUF.

The West India Mid-Shelf Front (WIMSF, 9) consists of two parts, one close to the coast and the other closer to the $200 \mathrm{~m}$ isobath in the northeastern Arabian Sea (NEAS). This front is seen during November-April, but the FPI is high even in the waters between the two parts of the WIMSF during February-April, when the high-FPI regime is broad in the NEAS.

The West India Shelf-Slope Front (WISSF, 10) is seen during November-April, with the high FPI evident during December-March, along the shelfbreak ( $\sim 200 \mathrm{~m}$ isobath) in the northern part of the eastern Arabian Sea. Although BC07 suggests that the WISSF extends all along the shelf break off the Indian west coast, we do not find evidence for it south of $\sim 16^{\circ} \mathrm{N}$.

The Gulf of Mannar Front (GMF, 11) is evident as a regime of high FPI near the northern boundary of the Gulf of Mannar between India and Sri Lanka (figure 1). It was not reported by BC07, but shows 
up in our analysis along the shelf break in the gulf, suggesting it is a shelf-slope front like the WISSF or the PUF. The GMF appears in June and July as a continuous regime of high FPI extending from the northern Gulf of Mannar to the coast of India bordering this gulf. The high FPI in the western gulf disappears during August-September, when the GMF is at its peak. The GMF weakens in October and disappears in November. It is seen again during December-January, but not in February. During March-April, it is weak, but still evident in the northern gulf before disappearing in May. Therefore, unlike the other fronts, the GMF is more intermittent, existing for a few months at a time before disappearing altogether for a month or more. Over the year, however, it is seen during 9 months of the year.

The East Ceylon Front (ECF, 12) is not seen at the location marked by $\mathrm{BC} 07$ and does not appear in the annual FPI map. FPI higher than in the surrounding ocean is evident, however, to the west of the BC07 curve during May, September and December, and to its east during June, suggesting that there may be a broader regime of high FPI east of Sri Lanka (Ceylon).

The Palk Strait Front (PSF, 13) appears as a regime of slightly higher FPI compared to the surrounding ocean at the northeastern boundary of the strait between the coast of India and the northern tip of Sri Lanka; this location is to the west of the curve marked by $\mathrm{BC} 07$ and suggests that the location of the PSF is also determined by bathymetry. The PSF is much weaker than the GMF, but exists during March-September.

The Ganga-Brahmaputra Estuarine Front (GBEF, 14) exists at the interface of the fresher water debouched into the northern BoB by the Ganga-Brahmaputra system and the saltier oceanic waters. Data are not available in the domain of this front during June-July, but available data suggest it is not evident when the discharge peaks during the summer monsoon: the front is not seen during August-September and exists as a regime of moderately high FPI during October-November before peaking during January-February. It is not seen during MarchMay. This seasonal cycle suggests that the front, even if it exists due to the salinity gradient, is controlled by the circulation.

The Myanmar Shelf-Slope Front (MSSF, 15) exists off the west coast of Myanmar during November-February. Although data are not available during May-September, the absence of this front during March-April and October suggests that it is limited to this season.

The Irrawaddy Estuarine Front (IrEF, 16) is maintained by the discharge from the Irrawaddy river (BC07), but its existence being limited to December-January and April suggests that the circulation of the Andaman Sea may exercise a control. Lack of data during May-September makes it impossible to judge if the IrEF exists during the summer monsoon, when the Irrawady discharge peaks.

The Thailand Shelf-Slope Front (TSSF, 17) was identified by $\mathrm{BC} 07$ along the eastern boundary of the Andaman Sea, but is not seen in our analysis. As for the IrEF, data are not available in its domain during May-September.

\section{Discussion}

Our analysis using 14 years (2003-2016) of MODIS Aqua SST data shows considerable seasonal variation in the SST fronts identified by $\mathrm{BC} 07$ and associated with LMEs in the NIO. One of the 14 fronts identified by BC07, the TSSF, is not seen in our analysis, and another, the ECF, shows up as a broad patch of high FPI (in comparison with the surrounding ocean) during a few months (figure 2 and table 1). Of these 14 fronts, only the PGF exists throughout the year, but its location shifts across the Persian Gulf (figure 2). A front mentioned by BC07 is shown to exist seasonally off the coast of Pakistan (PUF) and one new front, GMF, has been identified along the shelf-break in the Gulf of Mannar. We have also separated the weak front associated with the Somali Current, the SCF, from the stronger fronts, the SGF, associated with the gyres (the Southern Gyre and the Great Whirl) seen off Somalia.

Although clouds lead to data gaps, particularly during the summer monsoon, over parts of the domain (see figure S1), the available data are sufficient to permit the inference that only the PGF in the Persian Gulf exists throughout the year, but even the PGF moves across the gulf over the year. The other fronts exist only over a part of the year.

While we do not explore the reason for the existence of these fronts, their location suggests a forcing mechanism. Of these 17 fronts, eight are associated with the shelf-break - SCF, OCF, PUF, WISSF, GMF, PSF, MSSF and TSSF (which is not seen in our analysis) - and three with river discharge through large estuaries - IEF, GBEF and 
IrEF. Two fronts - GAF and GOF - are seen at the mouths of gulfs adjacent to the Arabian Sea and are probably also associated with temperature and salinity gradients resulting from the mixing between the more saline waters of these gulfs and the Arabian Sea. Therefore, 13 of the 17 fronts are either associated with topographic controls or temperature and salinity gradients created by the mixing of different water masses. The SGF is associated with the strong gyres that form offshore of the Somali Current and are therefore also associated with the strong gradients across these eddies. Only three fronts - the PGF, which lies within the shallow Persian Gulf; the WIMSF, which lies in the shallow mid-shelf regime of the NEAS; and the ECF, which lies off the east coast of Sri Lanka are due to other causes.

What is intriguing is the absence of a strong upwelling front off Somalia, which is considered to be the strongest upwelling regime in the NIO; although $\mathrm{BC} 07$ identified the SCF as a persistent front, we find only a weak SCF exists over a part of the shelf-slope boundary off Somalia during MayJuly. Likewise, the coastal region off Oman, which is the next strongest upwelling regime, harbours a weak OCF. Neither the SCF nor the OCF is as distinct as even the MSSF off the west coast of Myanmar, which is an eastern ocean boundary. The WISSF too occurs north of $16^{\circ} \mathrm{N}$, where the upwelling is weaker than off southwest India (Shankar et al. 2002). Hence, in contrast to the prediction of Evans and Brown (1981), that the strongest SST fronts in the tropical oceans are likely to occur in the upwelling regimes associated with western-boundary currents, the strong upwelling regimes of the NIO, even if seasonal, are not associated with strong SST fronts. A possible reason for the weak OCF off Oman is that the upwelled waters do not tend to move offshore in a classical Ekman drift, but move out of the coastal regime in jets or squirts (Böhm et al. 1999). Lack of data off southwest India during the summer monsoon is a likely reason for the absence of fronts in this upwelling regime (figure 2), but the absence of a strong SCF off Somalia, where data are not lacking, is intriguing.

The importance of these SST fronts is due to the potential implications for the marine ecosystem, with even weaker frontal systems having been shown to harbour an increase in chlorophyll- $a$ (Vipin et al. 2015), and fisheries (Solanki et al. 2008). Therefore, the physical forcing of these persistent fronts and their association with potential fishery zones (Solanki et al. 2008) needs to be investigated.

\section{Acknowledgements}

Kankan Sarkar and Shrikant Dora acknowledge the Academy of Scientific and Innovative Research (AcSIR) and the financial support from the Council of Scientific and Industrial Research (CSIR), India. This research was supported by funds from CSIR under the OCEAN FINDER programme during 2012-2017 and TRIMFish from April 2017 onwards. MODIS Aqua SST data were downloaded from OceanColor group website; we are grateful to the OceanColor group for providing these data. The figures have been plotted using Ferret. This is CSIR-NIO contribution no. 6296 .

\section{References}

Belkin I M and Cornillon P 2007 Fronts in the world ocean's large marine ecosystems; In: ICES CM 2007/D:21 (Comparative marine ecosystem structure and function: Descriptors and characteristics), International Council for the Exploration of the Sea (ICES).

Belkin I M, Cornillon P and Sherman K 2009 Fronts in large marine ecosystems; Prog. Oceanogr. 81 223-236.

Böhm E, Morrison J M, Manghnani V, Kim H S and Flagg C N 1999 The Ras al Hadd Jet: Remotely sensed and acoustic Doppler current profiler observations in 19941995; Deep-Sea Res. II 46 1531-1549.

Bruce J G 1968 Comparison of near surface dynamic topography during the two monsoons in the western Indian Ocean; Deep-Sea Res. 15 665-677.

Cayula J F and Cornillon P 1992 Edge detection algorithm for SST images; J. Atmos. Ocean. Tech. 9 67-80.

Evans R H and Brown O B 1981 Propagation of thermal fronts in the Somali current system; Deep-Sea Res. $\mathbf{2 8}$ 521-527.

Hickox R, Belkin I, Cornillon P and Shan Z 2000 Climatology and seasonal variability of ocean fronts in the East China, Yellow and Bohai seas from satellite SST data; Geophys. Res. Lett. 27 2945-2948.

Mahadevan A 2014 Ocean science: Eddy effects on biogeochemistry; Nature 506 168-169.

Maul G A, Williams F, Roffer M and Sousa F M 1984 Remotely sensed oceanographic patterns and variability of bluefin tuna catch in the Gulf of Mexico; Oceanol. Acta 7 469-479.

Miller P I 2009 Composite front maps for improved visibility of dynamic sea-surface features on cloudy SeaWiFS and AVHRR data; J. Mar. Syst. 78 327-336.

Roberts J J, Best B D, Dunn D C, Treml E A and Halpin P N 2010 Marine geospatial ecology tools: An integrated framework for ecological geoprocessing with ArcGIS, Python, R, MATLAB, and C++; Environ. Modell. Softw. 
25 1197-1207; https://doi.org/10.1016/j.envsoft.2010.03. 029.

Sarkar K, Aparna S G and Shankar D 2015 Sea surface temperature fronts in the NIO; In: National conference on exploring advances in mathematics, Department of Mathematics, University of Gour Banga, West Bengal, India.

Shankar D, Vinayachandran P N and Unnikrishnan A S 2002 The monsoon currents in the north Indian Ocean; Progr. Oceanogr. 52 63-120.

Solanki H U, Mankodi P C, Dwivedi R M and Nayak S R 2008 Satellite observations of main oceanographic processes to identify ecological associations in the
Northern Arabian Sea for fishery resources exploration; Hydrobiologia 612 269-279.

Ullman D S and Cornillon P C 1999 Satellite-derived sea surface temperature fronts on the continental shelf off the northeast U.S. coast; J. Geophys. Res. 104 23,45923,478 .

Vipin P, Sarkar K, Aparna S G, Shankar D, Sarma V V S S, Gracias D G, Krishna M S, Srikanth G, Mandal R, Rao E P R and Rao N S 2015 Evolution and sub-surface characteristics of a sea-surface temperature filament and front in the northeastern Arabian Sea during NovemberDecember 2012; J. Mar. Syst. 150 1-11; https://doi.org/ 10.1016/j.jmarsys.2015.05.003.

Corresponding editor: C GnANASEelan 